\title{
Top coal caving parameters of the thick lower seam in ultra-close multiple seams with combined mining
}

Ningbo Zhang ( $\square$ znbcumt@126.com )

China University of Mining and Technology

Changyou Liu ( $\nabla$ cyliucumt@126.com )

China University of Mining and Technology

Jingfeng Zhou

China University of Mining and Technology

Fengqi Guo

China University of Mining and Technology

Research

Keywords: ultra-close multiple- seams; thick lower seam; combined mining; top coal caving parameters

Posted Date: May 7th, 2020

DOI: https://doi.org/10.21203/rs.3.rs-24890/v1

License: (c) (i) This work is licensed under a Creative Commons Attribution 4.0 International License.

Read Full License 


\title{
Top coal caving parameters of the thick lower seam in ultra- close multiple seams with combined mining
}

\author{
ZHANG Ningbo $^{1,2 *}$, LIU Changyou ${ }^{1,2 *}$, ZHOU Jinfeng ${ }^{3}$, GUO Fengqi ${ }^{1,2}$ \\ 1. School of Mines, Key Laboratory of Deep Coal Resource Mining, Ministry of Education of China, China \\ University of Mining and Technology, Xuzhou, Jiangsu 221116, China \\ 2. State Key Laboratory of Coal Resources and Mine Safety, China University of Mining and Technology, \\ Xuzhou, Jiangsu 221116, China \\ 3. National Engineering Research Center for Coal Gas control, China University of Mining and Technology, \\ Xuzhou, Jiangsu 221116, China
}

\begin{abstract}
In the combined mining of ultra-close multiple seams with thin upper seam and thick lower seam, the mining of thin upper seam may lead to damages of the interburden and collapse of overburden. As a result, the roof of the thick lower seam in the fully mechanized caving process is turned into layers consisting of parts with different medium characteristics, in terms of damage severity and rock size, and the caving and recovery of top coal is significantly affected. Therefore, we propose a study of top coal caving and roof rock movement law under different fracture conditions based on two dimensional discrete element numerical simulation software program. The results revealed that roof rock channeling into the top coal was observed in the coal caving process in the presence of a huge difference between the lump sizes of roof rock and top coal of the lower seam, resulting in low recovery ratio. And the one cut/one caving upward caving pattern was the optimized top coal caving parameter. This study serves as a reference for future studies of top coal recovery in the combined mining of contiguous coal seams with thin upper seam and thick lower coal seam.

Key words: ultra-close multiple- seams; thick lower seam; combined mining; top coal caving parameters
\end{abstract}

\section{Introduction}

China is the largest coal producing country in the world with widely distributed coal reserves, and a variety of complicated mining conditions [1,2]. Coal seams usually occur in multiple-seams conditions and many of them are ultra-close adjacent seams [3]. In addition, with the increase of mine service life and mining intensity, the reserves of coal seams with better conditions are less, and the mine exploitation has been transferred from simple mining conditions to complex mining conditions, among which, the mining of adjacent seams has become an unavoidable problem [4]. The technical problems faced by the mining of ultra-close adjacent seams have also become the research hotspot of academia and production enterprises in coal field [4-7].

\footnotetext{
${ }^{*}$ Corresponding author. Tel.: +86-189-5223-1828, +86-135-8547-8385.

E-Mail address: znbcumt@126.com, cyliucumt@126.com;
} 
Under the condition of adjacent seams (especially the ultra-close multiple seams) with a thin upper seam and a thick lower seam, considering the mine capacity and the working-face replacement, the combined mining method is usually adopted[8,9]. That is, after the thin upper seam is mined at a certain distance, the thick lower seam will be extracted using fully mechanized top coal caving mining method and maintain an alternate distance from the upper seam[10-12]. Due to the small interburden thickness, the lower seam and interburden will be damaged by the abutment pressure caused by upper seam mining and re-damaged by another abutment pressure caused by the lower seam mining[13]. The strata above the top coal of the lower seam are the interburden strata which have already been in the plastic damage, the caved broken immediate roof and the fractured main roof of the mined upper seam. Obviously, there are different dielectric properties and block of coal and gangue in the caving process of top coal belong to the lower seam. So the reasonable top coal caving parameters should be determined according to the characteristics of top coal and its roof, so as to facilitate the recovery of the top coal [14].

The contiguous seams mining technologies of ultra-close multiple- seams have been researched by many scholars and tremendous progress has been made. Sahoo, S.K. et.al. monitored the strata stresses in a contiguous seam depillaring working [15]. Meng, L. S. et.al analyzed the fissure evolution of overburden caused multiple-seams mining [16]. Zheng, C.S. et.al. determined the mining sequences of the contiguous seams through analyzing interburden's geomechanical properties[17]. Singh, R. et.al. researched the instability of interburden between adjacent seams in India [18]. Mandal, P.K. et.al. simulated the multi-seam interaction of ultra-close multiple- seams (the interburden is $3 \mathrm{~m}$ rock strata) [8]. Zhang, P.S, et.al analyzed the pillar size of ultra-close multiple- seams by FLAC [19].

Nevertheless, few studies have investigated the effects of upper seam mining on the fully mechanized top coal caving of lower thick seam. Since fully mechanized top coal caving mining has the advantages of high-production, high-efficiency, low development ratio, and low-cost, it has developed rapidly and become the most extensively used mining method [20-24]. However, the recovery of top coal in fully mechanized caving mining is greatly influenced by the broken characteristics of top coal and roof, the destruction of interlayer strata by upper seam mining cannot be neglected $[25,26]$. In this paper, a study of the effects of upper seam mining on the caving and movement of top coal of the lower thick seam using two-dimensional discrete-element simulation is proposed. Through comparing the caving of top coal in the mono-mining of thick seam (mono mining) with the combined mining of seams with upper thin seam and lower thick seam (combined mining), the effects of upper seam mining on the recovery of lower thick seam would be investigated and parameters for fully mechanized caving of lower thick seam would be determined.

\section{Seams preserving conditions and broken parameters}

\subsection{Seams preserving conditions}

In District 11, Quandian Colliery located in Henan Province of China, the minable 
coal seams were $2{ }_{1}$ coal seam and 23 coal seam. Panel 21-11070 and Panel 23-11070 were mined simultaneously at the first time. Preserved in the lower of the Shanxi Group, the $2{ }_{1}$ seam exhibited a minable part with a length of $650 \sim 750 \mathrm{~m}$, an average inclination angle of $25^{\circ}$ and an average seam thickness of $6.2 \mathrm{~m}$. Preserved in the mid-lower of the Shanxi Group, the 23 seam exhibited a workface with an average inclination angle of $25^{\circ}$ and an average seam thickness of $1.5 \mathrm{~m}$. The intermediate roof of $2_{3}$ seam was made up of mudstone and had an average thickness of $7 \mathrm{~m}$; the intermediate floor of $2{ }_{3}$ seam was made up of sandy mudstone and siltstone. The floor of $2_{3}$ seam was the roof of 21 seam and the $2{ }_{1}$ seam had a fine sandstone intermediate roof with a thickness of $5 \mathrm{~m}$ and a mudstone roof with a thickness of $3 \mathrm{~m}$ ( $1 \mathrm{~m}$ above and $2 \mathrm{~m}$ below the fine sandstone). Figure 1 shows the composite columnar section of the coal-bearing rock series.

\begin{tabular}{|c|c|c|}
\hline Type & Columar & Thickness(m) \\
\hline Fine sandstone & & 7.5 \\
\hline Mudstone & & 6.0 \\
\hline 23 coal seam & & 1.5 \\
\hline Mudstone & & 1.0 \\
\hline Fine sandstone & & 5.0 \\
\hline Mudstone & & 2.0 \\
\hline 21 coal seam & & 6.2 \\
\hline Mudstone & & 2.0 \\
\hline Fine sandstone & & 8.0 \\
\hline
\end{tabular}

Figure 1 The composite columnar section of the coal-bearing rock series.

\subsection{Determination of roof fracture parameters}

Due to the combined mining of $2_{1}$ seam and the $2_{3}$ seam, the abutment pressure caused by the mining process of the upper seam would damage the floor (roof of the lower seam), and its damage degree is gradually weakened from upper to lower. In the subsequent mining of the lower seam, the front abutment pressure will cause further damage to the interburden, and the strata broken size was further decreased.

According to the field observation, the mudstone immediate roof caved and broken when the upper thin seam was mined, the breaking fragmentation is small, and the average block diameter is $0.2 \mathrm{~m}$. The mudstone and fine sandstone strata observed between two coal seams were affected by the mining of upper thin seam too, the plastic damage degree from strong to weak is the upper mudstone, the middle sandstone and the lower mudstone. But the cracking degree of the interlayer strata affected by the mining of thick lower seam from strong to weak is the lower mudstone, the middle sandstone and the upper mudstone. Figure 2 shows the lithology composition of thick lower seam and medium character after mining influence. 


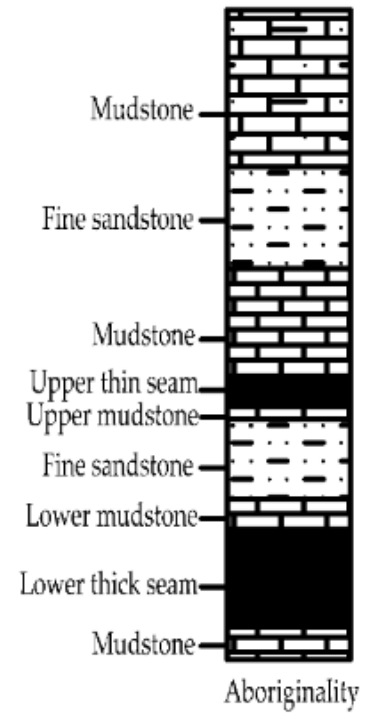

influence

Medium characteristics affected by the mining of upper seam

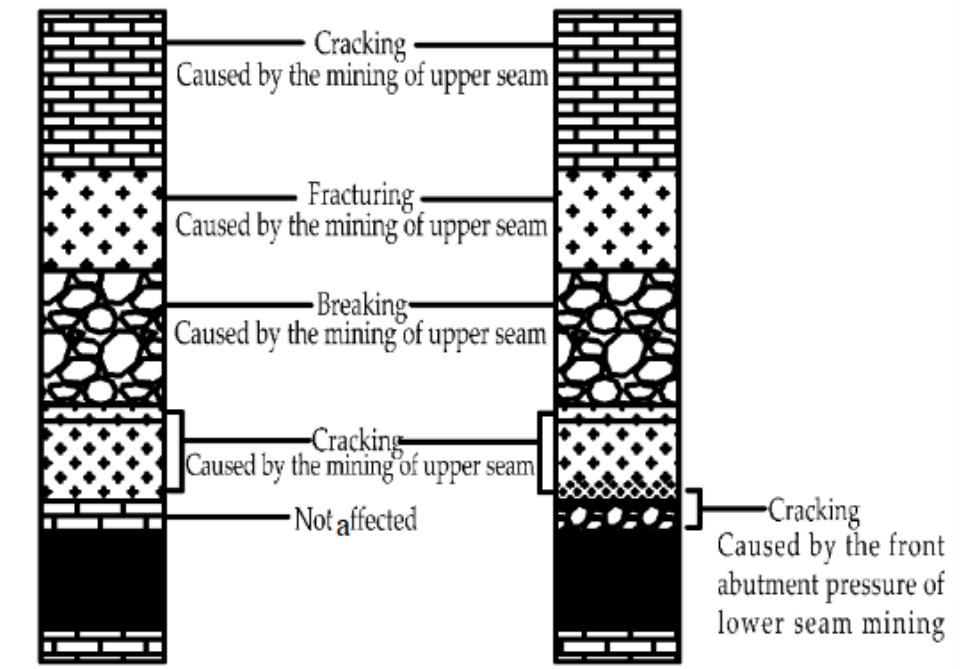

Medium characteristics affected by the front abutment pressure of lower thick seam mining

Figure 2 Lithology composition of thick lower seam and medium character after mining

After the effect of the mining-induced stress of upper seam and front abutment stress of lower seam, the damage of the interburden are as shown Table 1.

Table 1 Statistics of fragmentation size of coal and rock seams

\begin{tabular}{cccccc}
\hline & Immediate roof of & \multicolumn{3}{c}{ Interlayer strata } & 2 \\
\cline { 3 - 5 } & 23 seam & $\begin{array}{c}\text { Upper } \\
\text { mudstone }\end{array}$ & $\begin{array}{c}\text { Fine } \\
\text { sandstone }\end{array}$ & $\begin{array}{c}\text { Lower } \\
\text { mudstone }\end{array}$ & \\
\hline Size (m) & $0.1 \sim 0.3$ & $0.1 \sim 0.4$ & $0.3 \sim 0.6$ & $0.15 \sim 0.45$ & $0.02 \sim 0.2$ \\
Average (m) & 0.2 & 0.25 & 0.45 & 0.3 & 0.05 \\
\hline
\end{tabular}

From Table 1, when the caving mining of $2_{1}$ coal seam, the size distribution of interburden strata from big to small is mid fine sandstone, lower mudstone, upper mudstone, and top coal of $2_{1}$ seam.

\subsection{Modelling for calculation}

Based on the conditions of $2_{1}$ and $2_{3}$ seams in Quandian Colliery, Particle Flow Code (PFC) models were established to investigate the effect of different roof broken size characteristics on the caving and movement of top-coal of the lower seam. The topcoal caving parameters were optimized based on the recovery ratio and the waste ratio. Because the overlying rock of top coal caving working-face would be established the equilibrium structure, the gravity of rock strata above the immediate roof would be not transmitted to the loosed top coal. Thus, the rock strata above the immediate roof of $2_{3}$ coal seam will be not simulated in the model and loosed top coal and roof rock flow under gravity. The model was designed with length of $41 \mathrm{~m}$ and height of $38 \mathrm{~m}$ in the strike-direction, and length of $16.56 \mathrm{~m}$ and height of $32.42 \mathrm{~m}$ in the dip-direction. Laterally, the model's horizontal movement is restricted. At the bottom, the model's vertical movement is restricted. Six layers from the lower seam to the intermediate roof 
of the upper seam were established and the geophysical properties of these layers are shown in Table 2.

Table 2. Geophysical properties of different layers in the model

\begin{tabular}{ccccccccc}
\hline $\begin{array}{c}\text { Layer } \\
\text { number }\end{array}$ & Color & Type & $\begin{array}{c}\text { Normal } \\
\text { stiffness } \\
(\mathrm{Gpa})\end{array}$ & $\begin{array}{c}\text { Shear } \\
\text { stiffness } \\
(\mathrm{Gpa})\end{array}$ & $\begin{array}{c}\text { Unit } \\
\text { weight } \\
\left(\mathrm{kN} / \mathrm{m}^{3}\right)\end{array}$ & $\begin{array}{c}\text { Upper seam } \\
\text { unmined } \\
\text { /mined } \\
\text { equivalent } \\
\text { ball radius } \\
(\mathrm{m})\end{array}$ & Porosity & Friction coefficient \\
\hline 1 & Green & Intermediate roof & 5 & 5 & 2550 & $0.1 / 0.1$ & 0.4 & 0.5 \\
2 & Black & upper coal seam & 4 & 4 & 1400 & $0.08 / 0.08$ & 0.4 & 0.5 \\
3 & Blue & upper mudstone & 4 & 4 & 2550 & $0.18 / 0.12$ & 0.4 & 0.5 \\
4 & Yellow & Fine sandstone & 6 & 6 & 2650 & $0.20 / 0.16$ & 0.4 & 0.5 \\
5 & Red & lower mudstone & 4 & 4 & 2550 & $0.16 / 0.12$ & 0.4 & 0.5 \\
6 & Black & Lower coal seam & 4 & 4 & 1400 & $0.08 / 0.08$ & 0.4 & 0.5 \\
\hline
\end{tabular}

The calculation models along the strike and dip-directions are shown in Figure 3.

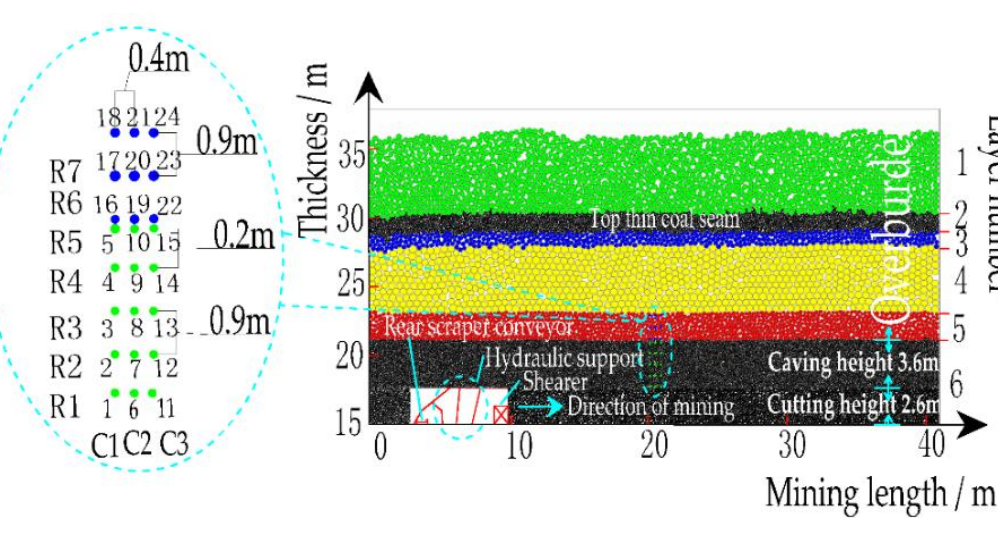

(a)

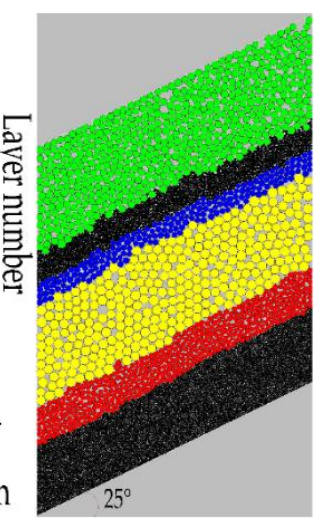

(b)

Figure 3 Models for mining (a) along the seam strike direction; (b) along the seam dip direction

The layers in the model were labelled with different colors: the black layers at bottom and on top were the $2{ }_{1}$ coal seam and the $2_{3}$ coal seam, respectively; the red layer and the yellow layer were the mudstone floor and the fine sandstone roof of the 21 coal seam, respectively; the blue layer and the green layer were the mudstone floor and mudstone intermediate roof of the $2_{3}$ coal seam.

Simulations of the following situations were included in this project:

1) The caving process and the recovery ratio of top coal of the $2_{1}$ seam were simulated with a cutting web of $0.6 \mathrm{~m}$ and $1.2 \mathrm{~m}$ in both mono mining and combined mining.

2) The caving process and the recovery ratio of top coal of the $2{ }_{1}$ Seam in upward and downward mining patterns.

3 ) The motion law of top coal was simulated. 24 reference points in three rows (15 in the top coal body and 9 in the intermediate roof, vertical distance $=0.9 \mathrm{~m}$ and horizontal distance $=0.4 \mathrm{~m}$ ) were designed on top of the support, as shown in Figure 3. In this way, the movement of the top coal and roof above the support were investigated. 


\section{Caving and motion law of top coal and roof rock under different roof fracture conditions}

\subsection{Caving law of top coal and roof rock under different roof fracture conditions}

As shown in Figure 4(a), roof rock channeling into the top coal from the backside of the caving shield was observed in the mono mining, resulting in top coal loss. As shown in Figure 4(b), no roof rock channeling into the top coal was observed in the combined mining, and top coal/roof rock boundary shifted smoothly as a whole.

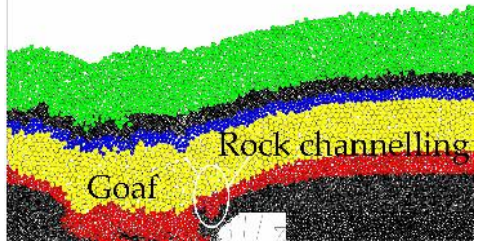

(a)

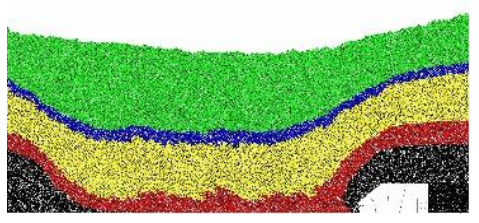

(b)

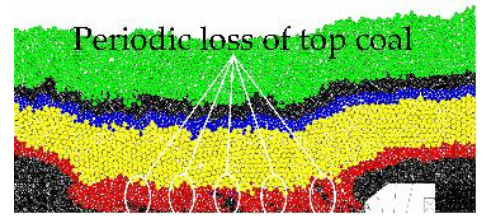

(c)

Figure 4 Loss of top coal in strike mining: (a) roof rock channeling in mono mining; (b) top coal caving in combined mining; (c) periodic loss of top coal in mono mining.

According to Figure 4, the probability of roof rock channeling into the top coal increased with coal/rock size variation. The top coal loss caused by roof rock channeling into the top coal was an accumulated result of several caving cycles and this loss was periodic. As shown in Figure 4(c), the period increased with top coal thickness, which can be attributed to the increased duration of roof rock movement.

In order to analyze the cause of the top coal cycle loss, the coal-gangue boundary in 30 web top coal caving simulation process are depicted separately, as shown in Figure 5 .

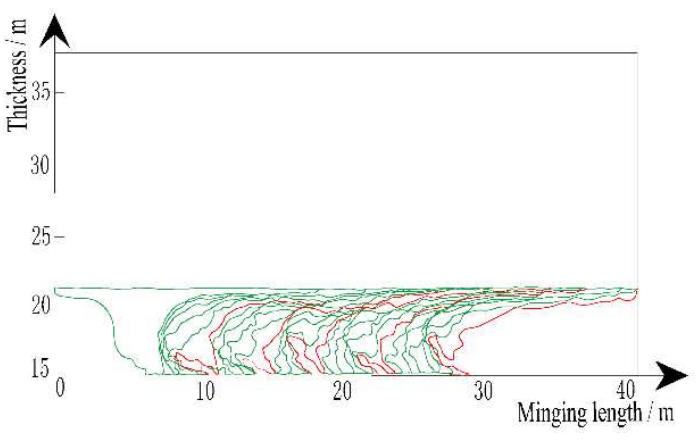

(a)

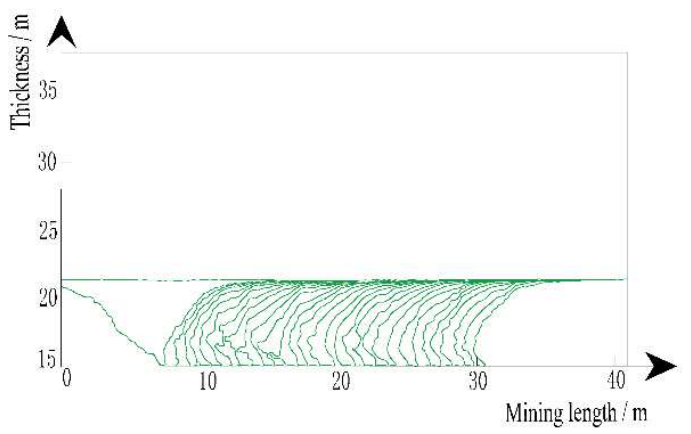

(b)

Figure 5 Coal-gangue boundary when (a) mono mining; (b) combined mining

As shown in Figure 5, compared with combined mining, the boundary incipient point of mono mining is farther, that is, the curvature of coal-gangue boundary line is smaller and more disordered when mono mining than that when combined mining. There are even two adjacent lines interacting. This is caused by the inconsistency of motion, which caused the channeling phenomenon. The result is some gangues would reach the caving opening before the coal and they would be lost in the gob. The gangue channeling leads to the coal caving in the top coal and the top coal is lost in the Gob area. The loss of top coal is cyclical, is a cumulative process, that is, the loss of top coal 
is not a certain caving web, but the accumulation of several webs, the cumulative process as shown in Figure 6.

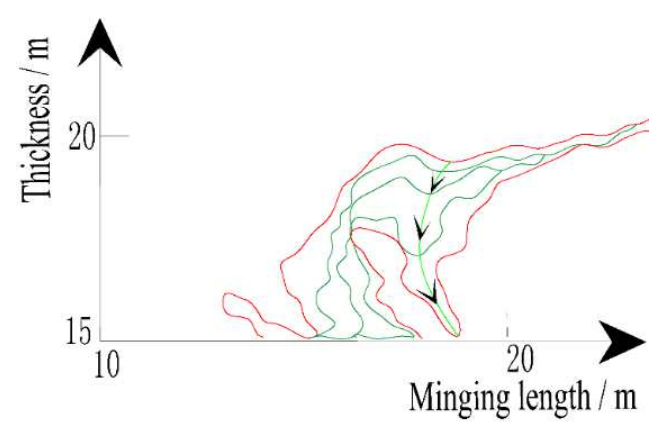

Figure 6 Cumulative process of gangue channeling

Addition, in someone caving process, the origin site of the caved body is a ellipsoids, which was called discharge ellipsoid. The long axis of the ellipsoid is roughly on the centerline of the caving opening. The size of discharge ellipsoid is depended on the curvature of coal-gangue boundary line, as shown in Figure 7.

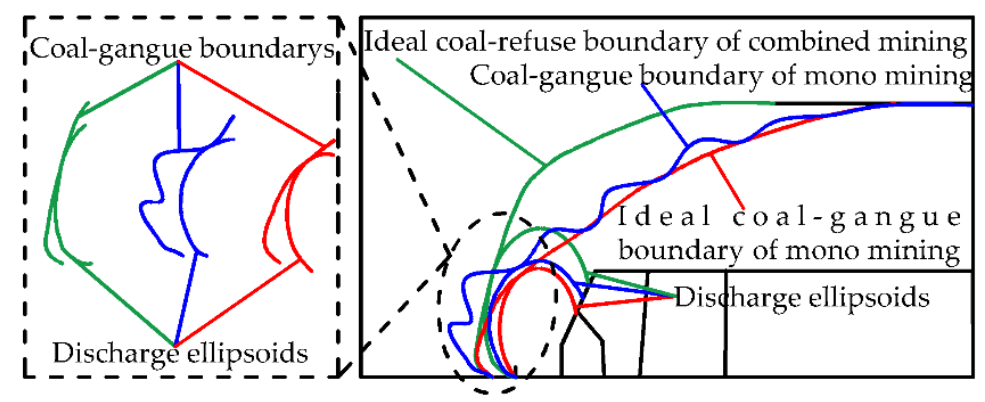

Figure 7 Relationship between the coal-gangue boundary and the discharge ellipsoid

From Figure 7, the lost zones of top coal with different curvature of coal gangue boundary line are the $\mathrm{E}, \mathrm{E}^{\prime}$ and $\mathrm{E}^{\prime \prime} \quad$ zone $\left(\mathrm{E}<\mathrm{E}^{\prime}<\mathrm{E}^{\prime \prime}\right)$. The smaller the curvature is, the larger the lost zone would be.

\subsection{Motion law of top coal and roof rock under different roof fracture conditions}

The reference point's motion law in the top coal recovery process were recorded and shown in Figure 8.

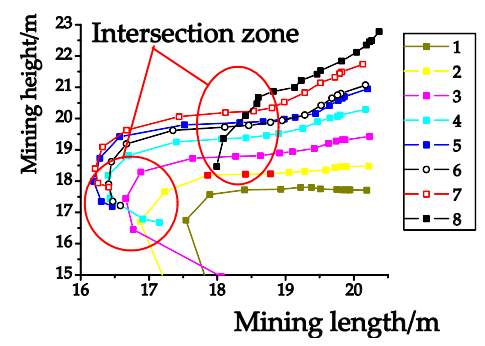

(a)

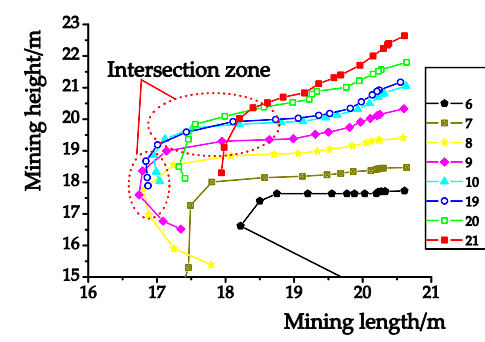

(b)

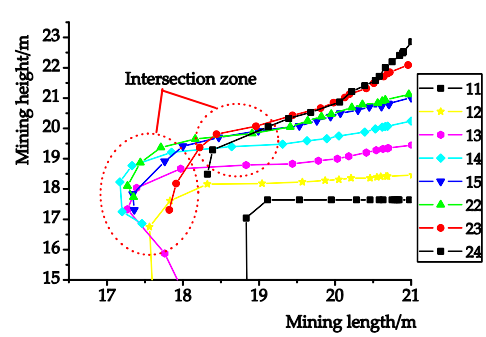

(c) 


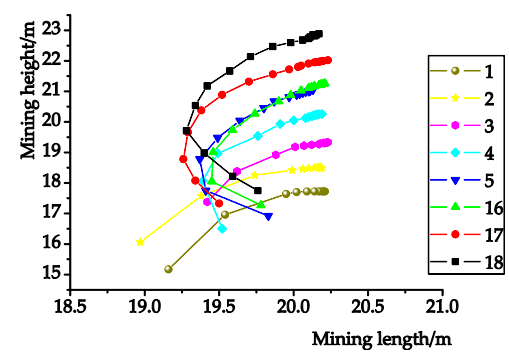

(d)

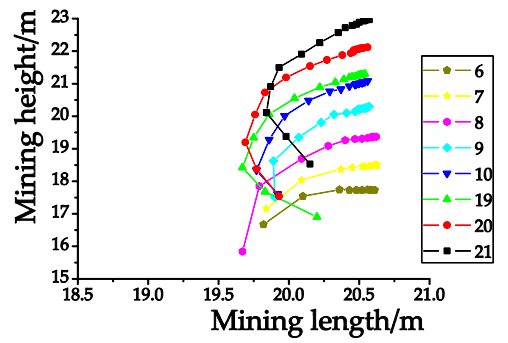

(e)

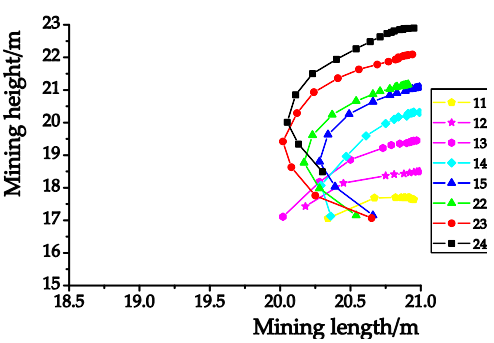

(f)

Figure 8 Motion of (a) Column 1 in mono mining; (b) Column 2 in mono mining; (c) Column in mono mining; (d) Column 1 in combined mining; (e) Column 2 in combined mining; (f)

Column 3 in combined mining.

In mono mining, two intersection points of the moving trails of reference points on the roof and in the top coal were observed: the first point was located above the caving shield and beneath the boundary; the second point was located behind the support and its height was slightly lower than the mining height. Roof rock merged into the coal flow at these locations and those merged at the first point blocked the channel, resulting in isolation of top coal in the mined-out zone. In combined mining, only the second intersection point mentioned above was observed and merged of roof rock to the coal flow was not observed. In mono mining, the reference points were moving horizontally in the early stage, while the height dropped drastically once the point approached the beam end of support. Additionally, the moving trails of reference points in mono mining were significantly longer than that in combined mining. As a result, the probability of roof rock channeling into the top coal was significantly increased in mono mining.

In summary, experimental and simulation results revealed that the medium characteristics (e.g. fracture conditions and roof rock size) had a significant effect on the caving and motion law of top coal and this effect increased with the variation of top coal and intermediate roof rock size.

\section{Determination of caving parameters and pattern}

\subsection{Mining pattern}

As indicated above, the roof rock size had a significant effect on the caving and recovery of top coal. In this section, the effects of $2{ }_{3}$ Seam mining on the caving of 21 Seam were determined based on the recovery ratio and the refuse content (waste rock ratio) to facilitate selection of mining pattern for contiguous seams.

The recovery ratio of top coal is calculated as follows:

$$
\eta=\frac{m}{\rho \times h \times l \times r}
$$

in the formula: $\eta$-top coal recovery ratio;

$\mathrm{m}$-the quality of the top coal released;

$\rho$-the density of the top coal, $1.37 \times 10^{3} \mathrm{~kg} / \mathrm{m}^{3}$;

$h$-The caving height, $3.6 \mathrm{~m}$; 
$l$-the support width, $1.5 \mathrm{~m}$;

$r$-mining interval, $0.6 \mathrm{~m}$ or $1.2 \mathrm{~m}$.

The formula (1) is used for calculating the recovery ratio in every caving interal.

Due to the stop principle of the top coal caving is the gangue been seen, so when there is guangue jumping, it will cause the caving stopped and the top coal will be accumulated behind the support. As a result of this situation, the quality of the top coal released each time is not equal, according to the calculation method of formula 1 , the recovery rate will be greater than $100 \%$ in some caving intervals (as show in figure 9,figure 10 and figure 11), but the overall average recovery rate is not affected.

Strike-direction models for mono mining and combined mining were established with one cut/one cave upward caving pattern and a caving web of $0.6 \mathrm{~m}$. The top coal recovery ratios and refuse content of strike-direction caving in mono mining and combined mining obtained are shown in Figure 9.

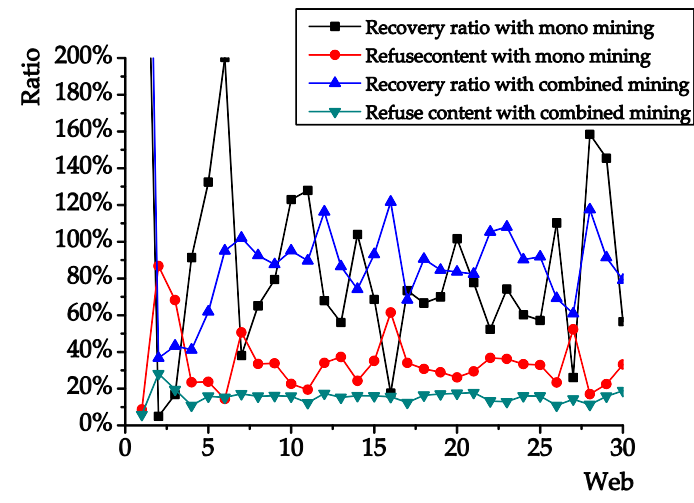

Figure 9 Top coal recovery ratios and refuse content of strike-direction caving in mono mining and combined mining (caving web $=0.6 \mathrm{~m}$ )

The average top coal recovery ratio and the waste ratio in mono mining were $90.2 \%$ and $34.7 \%$, respectively, excluding the first cycle. The average top coal recovery ratio and the waste ratio in combined mining were $94.6 \%$ and $27.6 \%$, respectively, excluding the first cycle. The maximum and minimum recovery ratios in mono mining were $240.4 \%$ and $14.4 \%$ of the average value, while the maximum and minimum recovery ratios in combined mining were $131.1 \%$ and $40.9 \%$. Therefore, it can be concluded that combined mining exhibited a better performance than mono mining did, in terms of both top coal recovery ratio and waste ratio.

\subsection{Caving web}

Models for combined mining of the $2{ }_{1}$ Seam with caving web of $0.6 \mathrm{~m}$ and $1.2 \mathrm{~m}$ were established to investigate the effects of caving web on top coal recovery based on recovery ratio and distribution of contact force field. Figure 10 shows the top coal recovery ratio and refuse content at $1.2 \mathrm{~m}$ caving web and $0.6 \mathrm{~m}$ caving web of combined mining. 


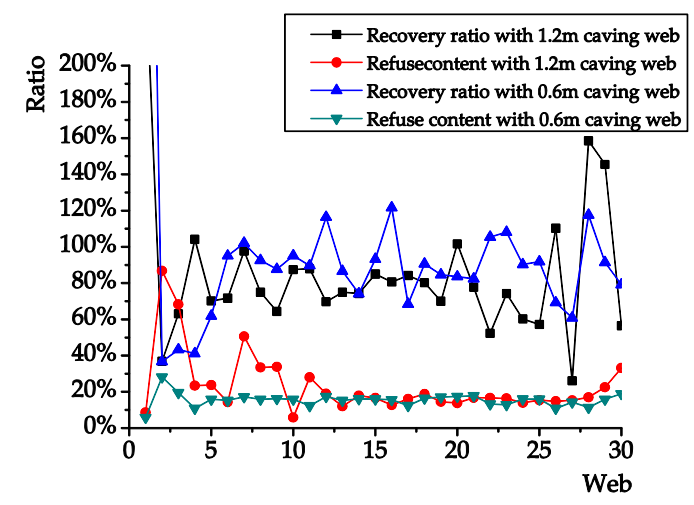

Figure 10 top coal recovery ratio and refuse content at $1.2 \mathrm{~m}$ caving web and $0.6 \mathrm{~m}$ caving web of combined mining.

The average top coal recovery ratio and the waste ratio in combined mining at a caving web of $1.2 \mathrm{~m}$ were $83.8 \%$ and $25.4 \%$, respectively, excluding the first cycle. The effect of caving web on the top coal recovery could be attributed to the large thickness $(3.8 \mathrm{~m})$ of the top coal of the $2{ }_{1}$ Seam. The waste rock reached the caving opening prior to the top coal behind the support in this case, resulting in reduced recovery ratio. Therefore, it was concluded that the caving web should be designed to be $0.6 \mathrm{~m}$.

\subsection{Caving pattern}

Models for combined mining of the $2{ }_{1}$ Seam using upward and downward caving patterns were established to investigate the effects of caving sequence on top coal recovery based on recovery ratio and waste ratio. The top coal losses were observed in both cases. In downward caving, roof rocks in the top mined-out zone moved rapidly to the caving opening due to the gravity effect, resulting in isolation of top coal. In upward caving, the top coal was dragged towards the mined-out zone by its gravity and roof rock reached the caving opening prior to top coal. Nevertheless, the top coal loss in upward caving was smaller than that in downward caving. The top coal recovery ratios in combined mining of the $2{ }_{1}$ Seam using upward and downward caving patterns are shown in Figure 11.

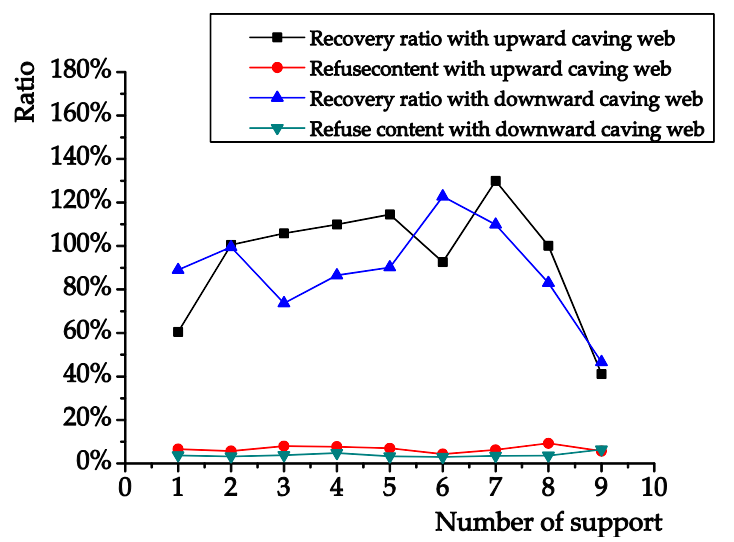

Figure 11 Top coal recovery ratios in combined mining of the $2_{1}$ Seam using upward and downward caving patterns

As observed, the recovery ratios in upward caving and downward caving cases 
were $95 \%$ and $89.1 \%$, respectively, while the difference of waste ratio in these two cases was $0.26 \%$. Hence, it can be concluded that upward caving should be selected under similar conditions.

\section{Effect of field application}

The combined mining of 21-11070 and 23-11070 working faces was started in May. 2017, and finished in Oct. 2018. The recovery ratio of top coal was shown in Table 3.

Table 3. Recovery ratio of top coal during the project study course

\begin{tabular}{ccccccccc}
\hline $\begin{array}{c}\text { Date of coal } \\
\text { mining (Y.M) }\end{array}$ & 2017.8 & 2017.9 & 2017.10 & 2017.11 & 2017.12 & 2018.1 & 2018.2 & 2018.3 \\
\hline $\begin{array}{c}\text { Recovery ratio } \\
(\%)\end{array}$ & 71.77 & 82.05 & 77.84 & 80.88 & 84.3 & 82.05 & 84 & 79.85 \\
\hline
\end{tabular}

As shown in the Table 3 , the average recovery ratio is $80.41 \%$ and the maximum recovery ratio is $84.3 \%$. So significant technical and economic benefits were obtained.

Moreover, the pattern of combined mining reduces the of subsidiary annual ring, equipment and personnel. The conveying system is simplified, the conveying route is shortened, and the utilization of the conveying equipment are improved, which reduced the number of jobs and increased the efficiency of production. Therefore, there are significant social benefits.

\section{Conclusions}

(1) The interburden fracture resulting from the combined mining of the upper seam had a significant effect on the top coal caving of the lower seam and movement of coal and rocks. In cases where the size of top coal lumps differs significantly from that of intermediate roof rocks, periodic losses of top coal due to roof rock channeling were observed in top coal caving processes.

(2) In cases where the size of top coal lumps differs significantly from that of intermediate roof rocks, two intersection points of the moving trails of reference points in the same row were observed, as well as trail crossing of reference points on the same horizontal line. As a result, roof rocks were mixed with coal earlier and the recovery ratio was reduced.

(3) The recovery ratio was significantly enhanced in cases where the size difference between top coal lumps and intermediate roof rocks was negligible. The combined mining was favored for top coal recovery of the $2{ }_{1}$ Seam and investigations on the effects of caving web and sequence on the top coal recovery revealed that the one cut/one cave upward caving pattern with a caving web of $0.6 \mathrm{~m}$ should be used for mining of the $2{ }_{1}$ Seam.

\section{Acknowledgments}

Financial supports for this work, provided by Independent Project of State Key Laboratory of Coal Resources and Safe Mining, CUMT(SKLCRSM20X), the National Natural Science Foundation of China (Grant No. 51704275), and China Postdoctoral Science Foundation (Grant No. 2019M661994), are gratefully acknowledged. 


\section{References}

1. Li, M.Q. World coal 2018-2050: World energy annual report (part 4). Peak Oil Barrel 2018.

2. Thielemann, T.; Schmidt, S.; Gerling, J.P. Lignite and hard coal: Energy suppliers for world needs until the year 2100 - an outlook. Int. J. Coal Geol. 2007, 72, 1-14.

3. Lu, Y.; Liu, C.Y.; Zhou, J.F.; Chen, X.H. Failure structure characteristics of strata with upper thin and lower thick strata in ultra-close coal seams with simultaneous mining and relationship between shield and surrounding rock. Journal of Mining and Safety Engineering 2017, 34, 832-837.

4. Liu, X.J.; Li, X.M.; Pan, W.D. Analysis on the floor stress distribution and roadway position in the close distance coal seams. Arab. J. Geosci. 2016, 9, 8.

5. Lu, Y.; Liu, C.Y. Mixed layout parameters of simultaneous mining roadways in close multiple-seam. Journal of Shandong University of Science and Technology 2015, 34, 67-77.

6. Ju, C.L.; Zhao, G.D.; Gao, F. Coal pillar size of ultra closed distance seam and layout of mining gateway. In Sustainable development of natural resources, pts 1-3, Trans Tech Publications Ltd: Durnten-Zurich, 2013; Vol. 616-618, pp 465-+.

7. Yan, H.; Zhang, J.X.; Zhang, S.; Zhou, N. Physical modeling of the controlled shaft deformation law during the solid backfill mining of ultra-close coal seams. B Eng Geol Environ 2019, 78, 37413754.

8. Mandal, P.K.; Singh, R.; Maiti, J.; Singh, A.K.; Kumar, R.; Sinha, A. Underpinning-based simultaneous extraction of contiguous sections of a thick coal seam under weak and laminated parting. Int. J. Rock Mech. Min. Sci. 2008, 45, 11-28.

9. Niu, W.J.; Fan, J.H.; Chen, Q.F.; Liu, Y.Z.; Destech Publicat, I. Mining response and superposition pattern of surrounding rock for multi-level simultaneous mining. International Conference on Energy and Environment Engineering (Iceee 2015) 2015, 484-489.

10. Yuan, Y.; Tu, S.H.; Lu, L.N.; Ma, X.T.; Gao, J. Unconventional staggered distance simultaneous mining theory in extremely close and thin coal seams and its application. In Proceedings of the international conference on mining science \& technology, Ge, S.; Liu, J.; Guo, C., Eds. Elsevier Science Bv: Amsterdam, 2009; Vol. 1, pp 288-293.

11. Kovalevska, I.; Symanovych, H.; Barabash, M.; Snihur, V. Research into rock pressure manifestations in interstratal rocks during descending and simultaneous mining of c-9 and c-10(top) coal seams. Min. Miner. Deposits 2017, 11, 50-56.

12. Kang, J.; Sun, G.Y.; Chen, H.B.; Yin, X.J. Study on stress distribution and transfer law of simultaneous mining in the ultra-close thin coal seams. International Mining Forum 2010: Mine Safety and Efficient Exploitation Facing Challenge of the 21st Century 2010, 87-90.

13. Zhang, B.S.; Kang, L.X.; Zhai, Y. Definition of ultra-close multiple-seam and its ground pressure behavior. proceedings of the 24th International Conference on Ground Control in Mining 2005, 110-113.

14. Zhou, J.F.; Liu, C.Y.; Lu, Y.; LI, J.W. Study of appropriate technological parameters for fully mechanized sublevel caving mining under gob of close seams. Coal Technology 2015, 34, 1-3.

15. Sahoo, S.K.; Galav, A.; Behera, B.; Sharma, S.K.; Singh, G.S.P. Strata control monitoring in a contiguous seam depillaring working. Proceedings of the Conference on Recent Advances in Rock Engineering (Rare 2016) 2016, 91, 348-352.

16. Meng, L.S.; Fan, D.Y.; Liu, X.S.; Li, Y. Fissure evolution of weak-cemented jurassic overburden induced by multiple-seam mining: A case study in western china. Energy Sources Part A-Recovery Util. Environ. Eff., 21. 
17. Zheng, C.S.; Kizil, M.S.; Aminossadati, S.M.; Chen, Z.W. Effects of geomechanical properties of interburden on the damage-based permeability variation in the underlying coal seam. J. Nat. Gas Sci. Eng. 2018, 55, 42-51.

18. Singh, R.; Singh, S.K.; Kushwaha, A.; Sinha, A. Stability of the parting between coal pillar workings in level contiguous seams during depillaring. Int. J. Rock Mech. Min. Sci. 2012, 55, 1-14.

19. Zhang, P.S.; Zhang, W.Q.; Yan, W.; Yu, H.L. Safety analysis for pillar of ally exploitation laneway in extreme close distance coal seam. Science Press Beijing: Beijing, 2004; Vol. 4, p 894-898.

20. Zhang, N.B.; Liu, C.Y.; Pei, M.S. Effects of caving-mining ratio on the coal and waste rocks gangue flows and the amount of cyclically caved coal in fully mechanized mining of super-thick coal seams. Int. J. Min. Sci. Technol. 2015, 25, 145-150.

21. Zhang, N.B.; Liu, C.Y.; Yang, P.J. Flow of top coal and roof rock and loss of top coal in fully mechanized top coal caving mining of extra thick coal seams. Arab. J. Geosci. 2016, 9, 9.

22. Wang, J. Engineering practice and theoretical progress of top-coal caving mining technology in china. Journal of China Coal Society 2018, 43, 43-51.

23. Liu, C. Development and thinking of full-mechanized mining theory and technology. Science and Technology of Datong Coal Mining Administration 2017, 154, 1-6.

24. Zhang, N.B.; Liu, C.Y. Radiation characteristics of natural gamma-ray from coal and gangue for recognition in top coal caving. Sci Rep-Uk 2018, 8, 9.

25. Liu, C.H., Bingxiang; Wu, Fengfeng; . Fragment dimension theory and its application in fully mechanized top coal caving. Journal of Mining and Safety Engineering $\backslash$ 2006, 23, 56-61.

26. Li, Z.; Xu, J.L.; Yu, S.C.; Ju, J.F.; Xu, J.M. Mechanism and prevention of a chock support failure in the longwall top-coal caving faces: A case study in datong coalfield, china. Energies 2018, 11. 
Figures

\begin{tabular}{|c|c|c|}
\hline Type & Columar & Thickness $(\mathrm{m})$ \\
\hline Fine sandstone & $\mathbf{3}$ & 7.5 \\
\hline Mudstone & & - \\
\hline 23 coal seam & & 6.0 \\
\hline Mudstone & & 1.5 \\
\hline Fine sandstone & & 1.0 \\
\hline Mudstone & & 5.0 \\
\hline 21 coal seam & & 2.0 \\
\hline Mudstone & & 6.2 \\
\hline Fine sandstone & & 2.0 \\
\hline
\end{tabular}

Figure 1

The composite columnar section of the coal-bearing rock series. 


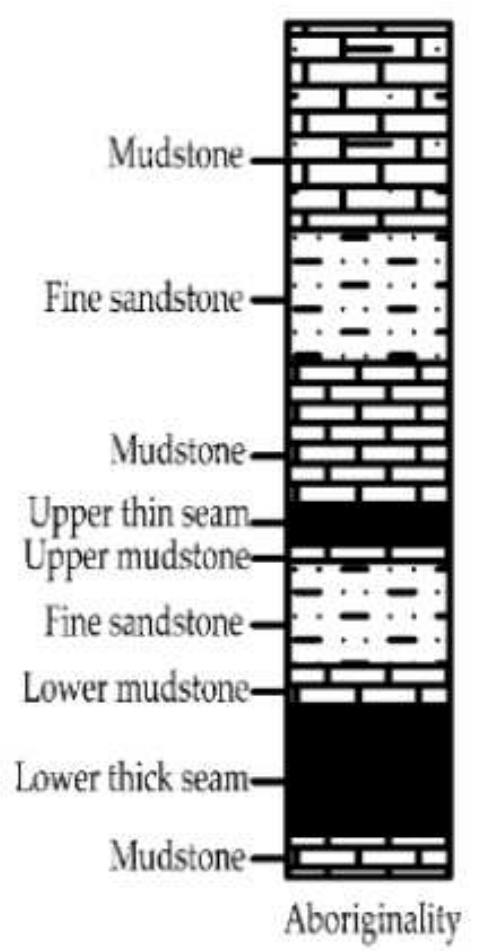

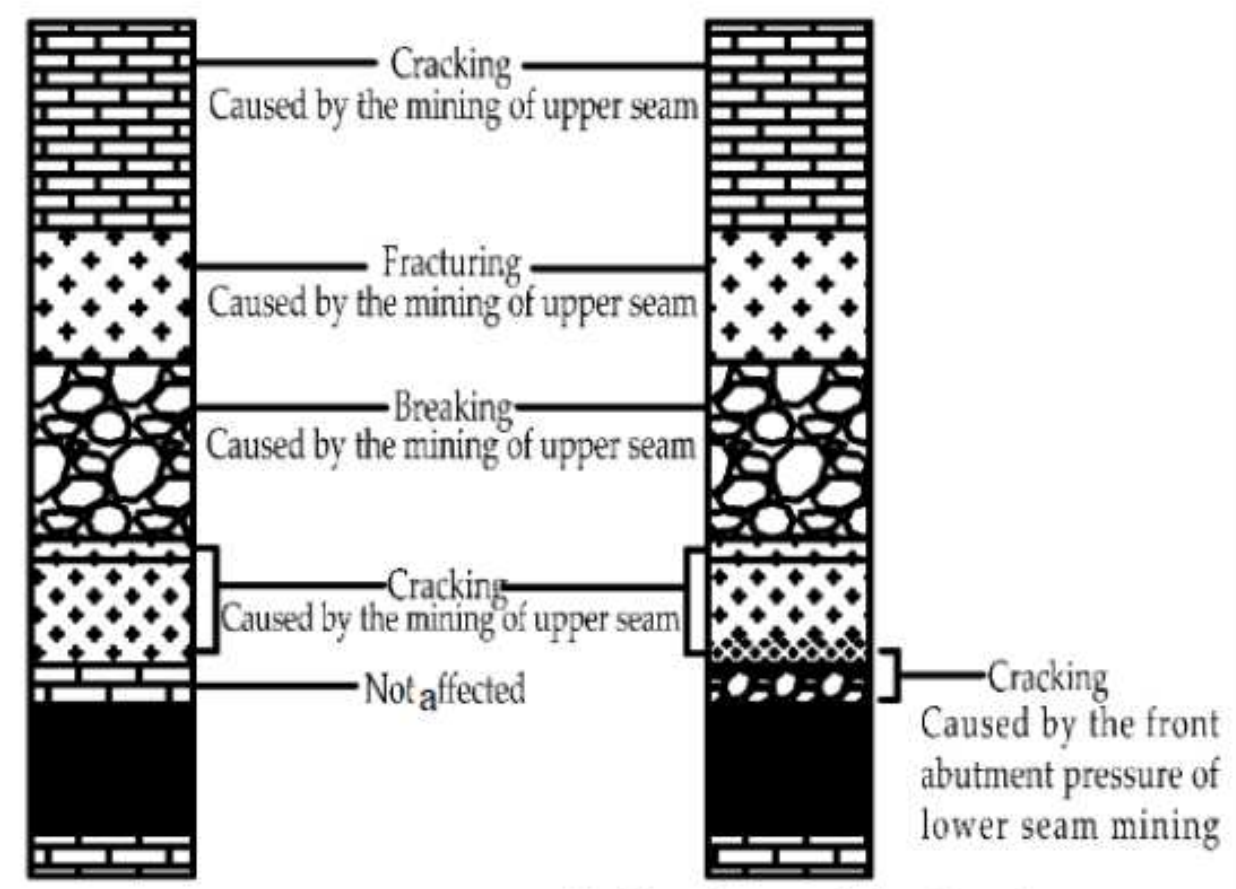

Medium characteristics affected by the mining of upper seam
Medium characteristics affected by the front abutment pressure of lower thick seam mining

\section{Figure 2}

Lithology composition of thick lower seam and medium character after mining influence

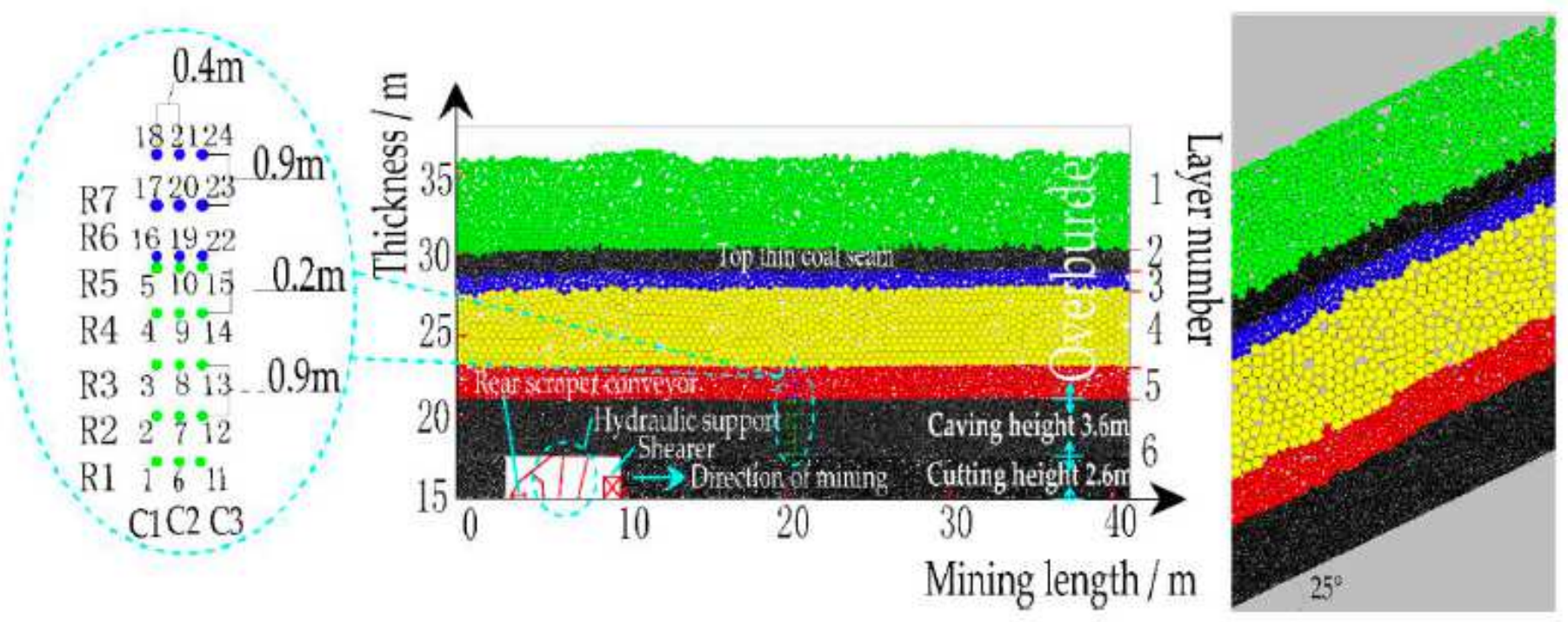

(a)

(b)

Figure 3

Models for mining (a) along the seam strike direction; (b) along the seam dip direction 


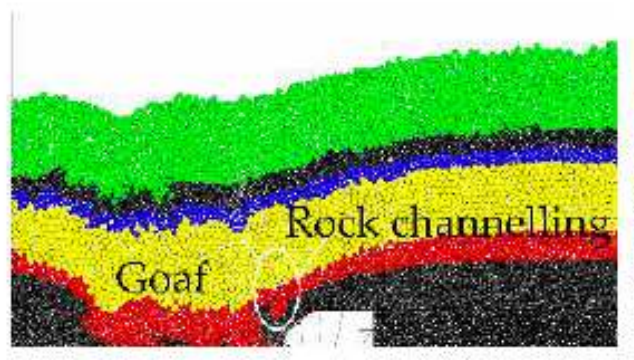

(a)

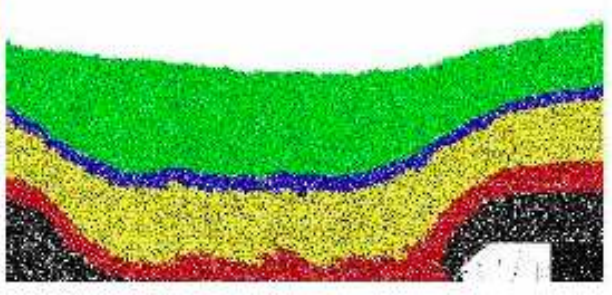

(b)

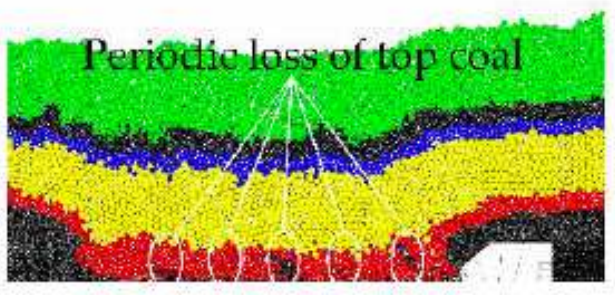

(c)

\section{Figure 4}

Loss of top coal in strike mining: (a) roof rock channeling in mono mining; (b) top coal caving in combined mining; (c) periodic loss of top coal in mono mining.

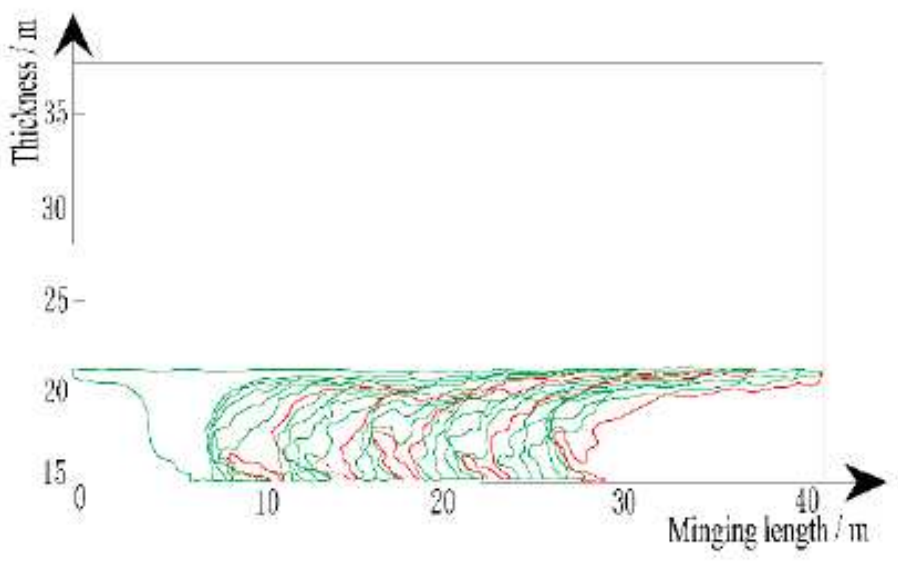

(a)

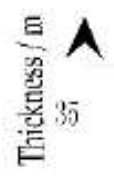

30

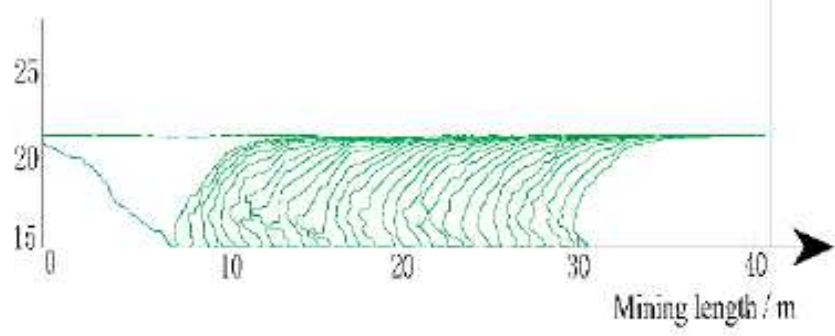

(b)

\section{Figure 5}

Coal-gangue boundary when (a) mono mining; (b) combined mining

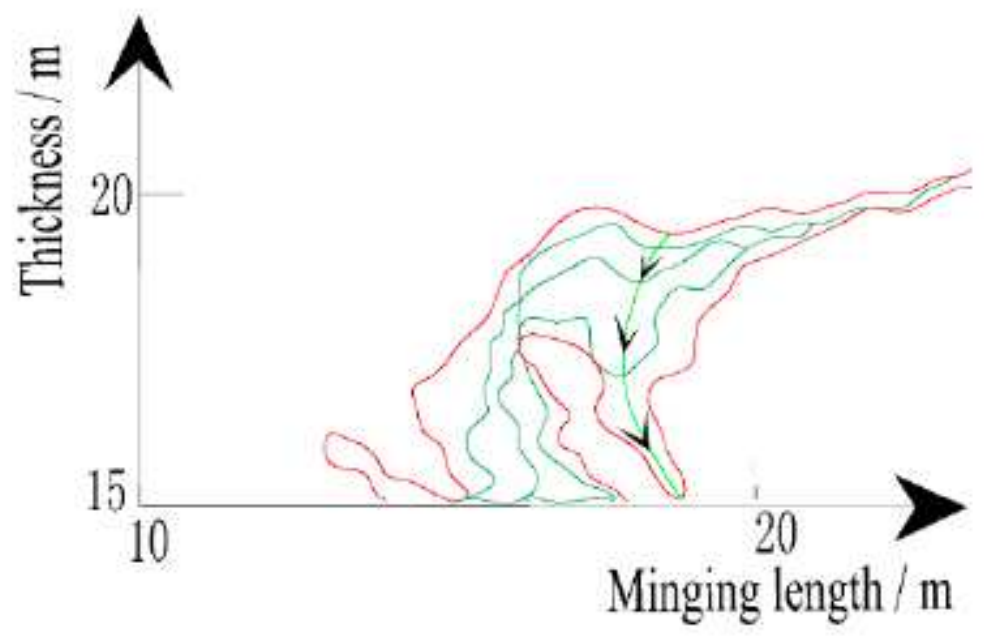

Figure 6 


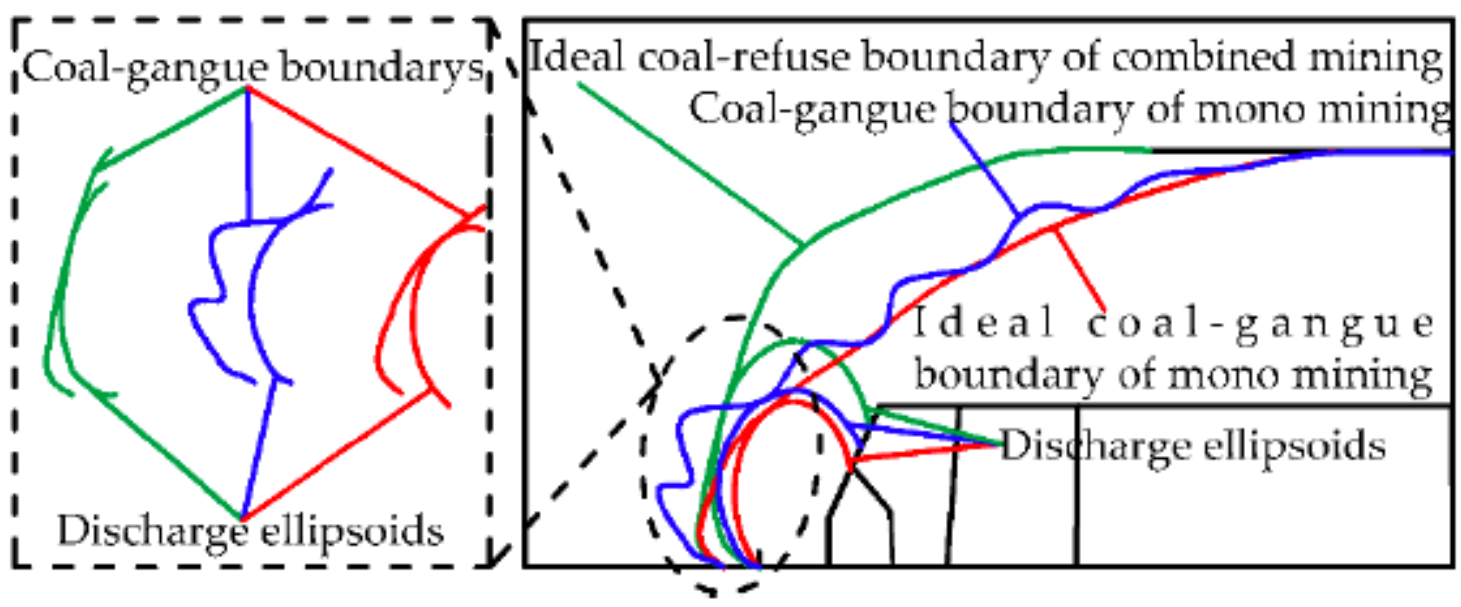

Figure 7

Relationship between the coal-gangue boundary and the discharge ellipsoid

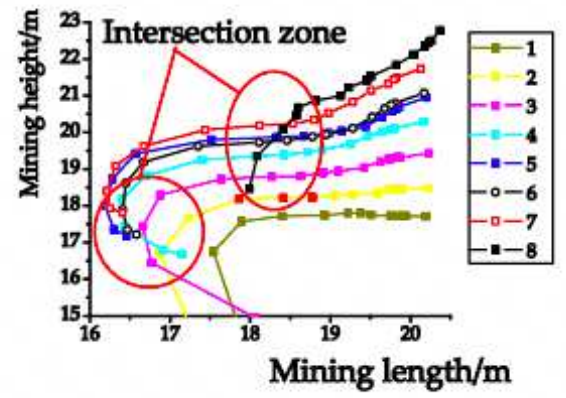

(a)

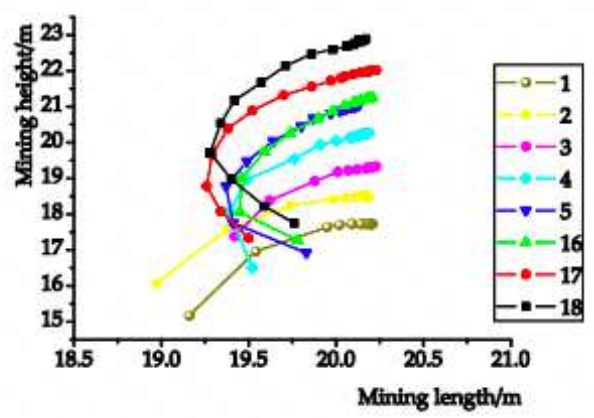

(d)

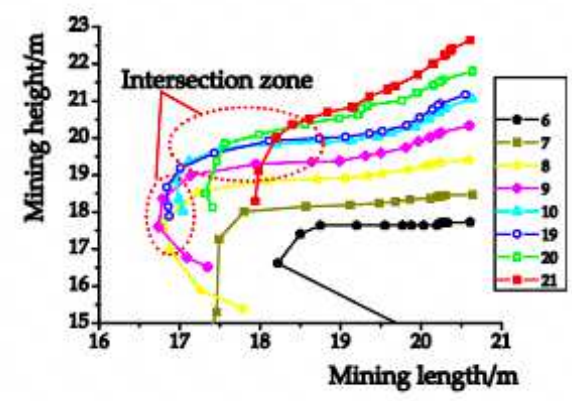

(b)

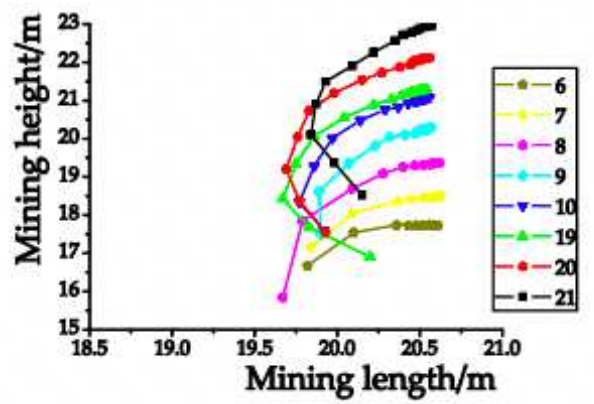

(e)

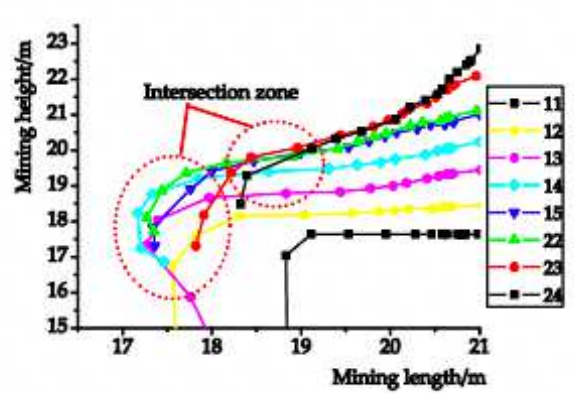

(c)

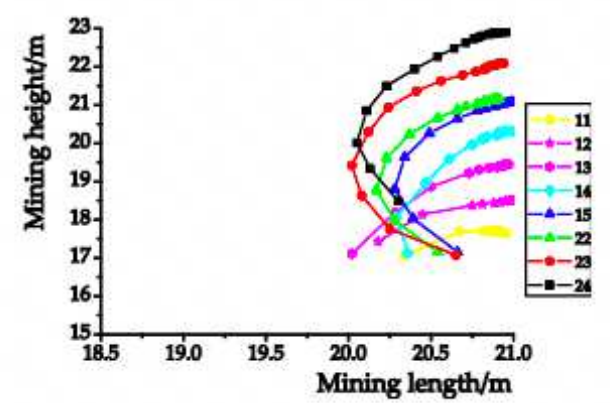

(f)

Figure 8

Motion of (a) Column 1 in mono mining; (b) Column 2 in mono mining; (c) Column in mono mining; (d) Column 1 in combined mining; (e) Column 2 in combined mining; (f) Column 3 in combined mining. 


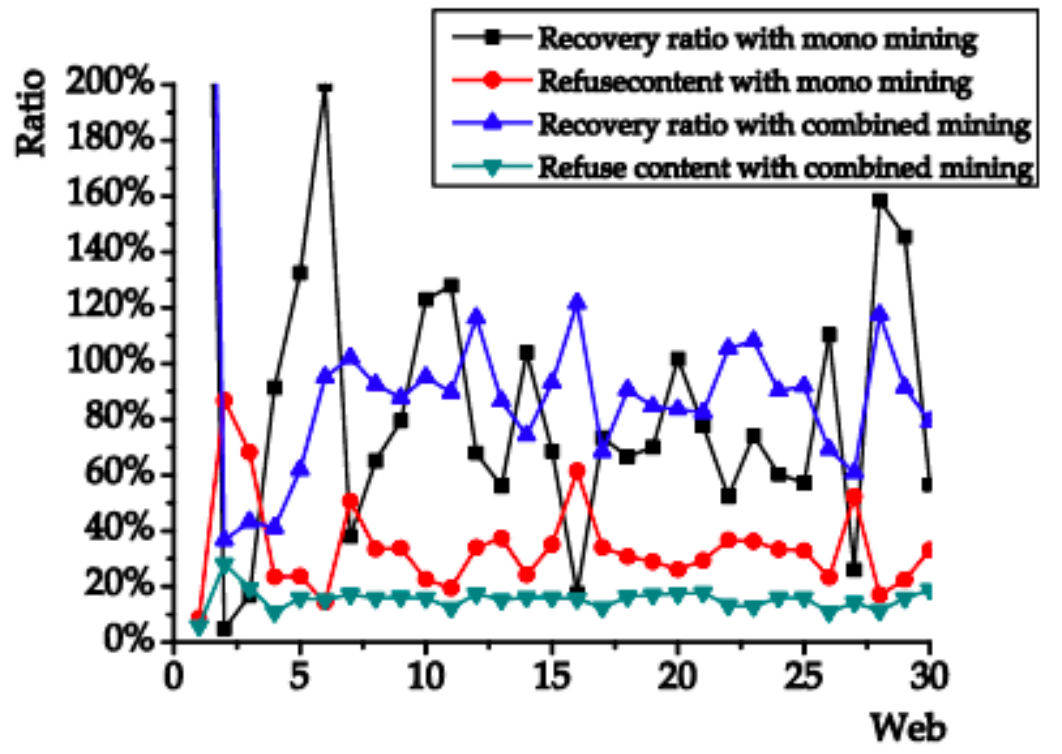

Figure 9

Top coal recovery ratios and refuse content of strike-direction caving in mono mining and combined mining (caving web $=0.6 \mathrm{~m}$ )

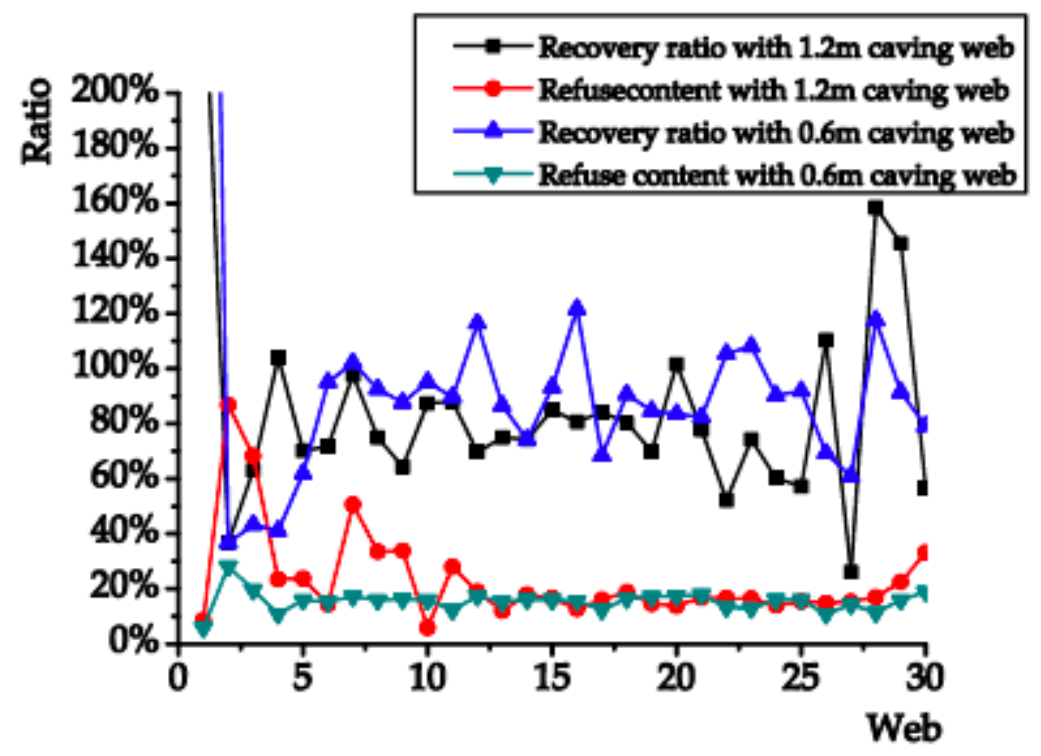

Figure 10

top coal recovery ratio and refuse content at $1.2 \mathrm{~m}$ caving web and $0.6 \mathrm{~m}$ caving web of combined mining. 


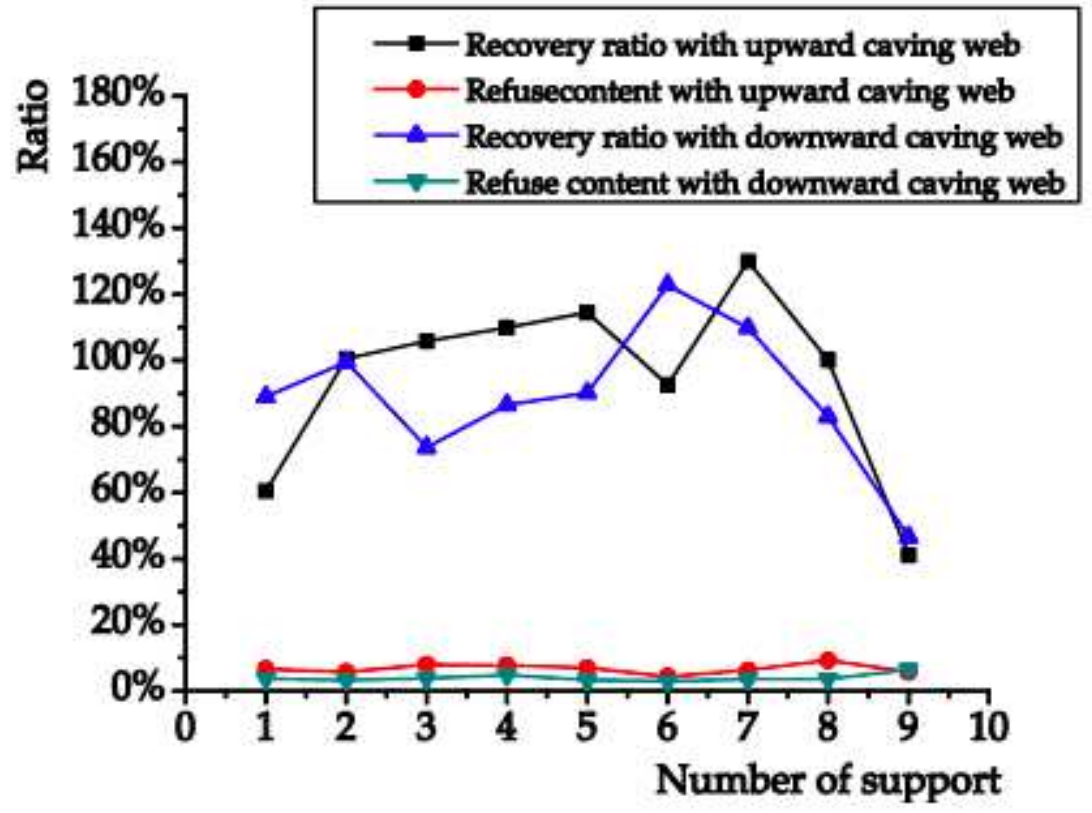

Figure 11

Top coal recovery ratios in combined mining of the 21 Seam using upward and downward caving patterns 